\title{
FEMINISMO, LITERATURA E UTOPIA: REFLEXÕES SOBRE UMA "FOTOGRAFIA"
}

\section{Ildney Cavalcanti*}

Resumo: Este trabalho examina algumas convergências entre os campos discursivos da teoria feminista, da literatura de autoria feminina e dos estudos da utopia. A partir dessa justaposição, será discutida uma perspectiva de leitura utópico-feminista baseada no conceito de um "outro lugar" (an elsewhere) do discurso e da representação, a partir de teorizações das pensadoras Julia Kristeva, Hélène Cixous, Luce Irigaray e Teresa de Lauretis. Propõe-se, com a presente discussão, que o dualismo observado nas especulações teóricas sobre o "outro lugar" do discurso seja abordado em seu caráter complementar: (a.) enquanto espaço de alteridade radical na escrita e na representação onde o desejo se inscreve, entendendo o "outro lugar" como elemento motivador da própria escritura; e (b.) como um espaço liminar que, ao situar-se dentro e fora das estruturas de poder existentes, permite perspectivas críticas e ações transformadoras. O entrecruzamento dessas posições será iluminado a partir de um olhar sobre o poema "Fotografia", de Adélia Prado.

Palavras-chave: Feminismo. Literatura. Utopia. Outro lugar (elsewhere).

Without utopianism, feminism will grind to a halt. ${ }^{1}$ Lucy Sargisson

Feminismo, literatura e utopia

Apesar de termos hoje em dia mil razões para suspeitar de palavras como "esperança" e "utopia", há sinais que evidenciam a sobrevivência, e, aqui e ali, um renascimento de idéias utópicas. Esse

* Doutora em English Studies pela University of Strahclyde, Escócia; atua como professora e pesquisadora no Programa de Pós-graduação em Letras e Lingüística (UFAL). É coordenadora do grupo de pesquisa Literatura e Utopia, vinculado ao PPGLL/UFAL, com auxílio da FAPEAL, e do GT A Mulher na Literatura, da ANPOLL.

1 "Sem o utopismo o feminismo desgastar-se-á até travar" (SARGISSON, 1996). Todas as traduções do inglês são minhas. 
renascimento pode ser observado concretamente na revisão radical, no âmbito de todas as esferas da experiência, proposta pelo movimento feminista. Um princípio utópico, caracterizado pela crítica ao presente e pela projeção de um futuro alternativo, age como ponto central para o movimento. Assim, não parece acidental que o próprio termo "feminismo" tenha sido sugerido por um pensador reformista no contexto do socialismo utópico. ${ }^{2}$ Afinal de contas, o movimento traz consigo esperanças e desejos de práticas históricas alternativas ou, nas palavras do filósofo Ernst Bloch (1995), de um porvir histórico denominado o "ainda-não".

De forma mais perceptível, a partir do movimento feminista das décadas de 60 e 70, observa-se, paralelamente ao feminismo manifestado através da militância política e da teoria e da crítica literárias, o surgimento de obras literárias de autoria feminina reveladoras de uma maior consciência do poder político inerente ao ato de escrever. Essa consciência foi notadamente articulada pela poeta e crítica norte-americana Adrienne Rich, que, numa frase que tem ressoado desde sua enunciação no início dos anos 70, colocou-se a favor de uma atitude revisionista em relação à literatura. Ela defende a "escritura enquanto revisão", definindo-a como "o ato de olhar para o passado, de ver com olhar renovado, de penetrar num velho texto a partir de um novo direcionamento crítico", num esforço para criar algo novo e como um "ato de sobrevivência" (1971, p. 167). ${ }^{3}$ Nessa passagem, é evidenciada sua preocupação com a tradição e o cânone, um aspecto fortemente salientado neste ensaio: "Precisamos conhecer a escritura do passado, e conhecê-la de forma diferente de como a temos conhecido; não para perpetuarmos uma tradição, mas para quebrarmos seu controle sobre nós" (p. 167-168). Apesar de esse argumento descrever uma contradição crucial e não resolvida da literatura e crítica feministas, ele ainda retém sua força original, que parece estar contida exatamente na tensão que a sustenta.

2 O termo, do qual o primeiro registro data da década de 1890 , tem sua origem no francês féminisme, criado pelo socialista utópico Charles Fourier (1772-1837). Cf. Honderich ed., 1995, p. 270.

3 "When we dead awaken: writing as revision", in Rich (1993, p. 166-177). 
O projeto de Rich sintetiza a dimensão utópica de uma escritura feminista, ao propor a desconstrução de um corpus literário tradicional hegemônico e historicamente flexionado no masculino, através da codificação do novo na reescritura. Nele estão presentes os elementos fundamentadores do direcionamento utópico: crítica e projeção.

A revisão feminista do cânone abarcou e abarca vários gêneros literários, e isto inclui as utopias canônicas, dentre as quais a República (c. 370 a.C.), de Platão, e a Utopia (1516), de Thomas More, são geralmente citadas como as obras representativas. ${ }^{4}$

Herland (1915), de Charlotte Perkins Gilman, ilustra a revisão feminista do subgênero em sua forma eutópica, com a descrição de um "bom lugar" separatista para as mulheres. Esse texto oferece uma crítica não apenas à sociedade patriarcal contemporânea, como também expõe a pseudo-universalidade das utopias literárias publicadas anteriormente. Já as distopias feministas, mais visíveis na cultura a partir dos anos 60, também apresentam uma escritura profundamente crítica e revisionista, porém, de forma duplamente perceptível. Primeiramente, porque elas reescrevem uma tradição literária de autoria masculina, conforme se pode ilustrar através da obra de Monique Wittig, Across the Acheron (1985), que constrói uma crítica a vários mitos do paraíso e do inferno, sendo que este último tem sua representação centrada na opressão de gênero na obra de Wittig, fator que inscreve o seu feminismo. Em segundo lugar, saliente-se o fato de as distopias efetuarem um outro tipo de escrita revisionista, no sentido em que elas emergem em nossa cultura também em resposta às eutopias literárias (e, no contexto da denominada crise da modernidade, que questionou as bases do próprio pensamento utópico). Desse modo, além de criticarem a sociedade contemporânea e revisarem uma tradição literária centrada na

4 Do trabalho arqueológico da crítica feminista resulta o enfoque no pioneirismo em termos da questão do gênero, no âmbito do subgênero da utopia literária, de La Cité des Dames (1405), de Christine de Pizan, que tem sido de modo geral negligenciado tanto pela crítica literária, quanto pelos compêndios históricos sobre utopismo literário, ambos de caráter mais tradicional. 
produção de autoria masculina, as distopias feministas também problematizam versões anteriores (e mais ingênuas) do "bom lugar" flexionadas no feminino, como a de Gilman.

Não é apenas através das estratégias formais associadas aos subgêneros literários da eutopia e da distopia que se pode observar uma disposição utópica na literatura. Sendo maior do que a dimensão formal, a tendência ou qualidade utópica de um texto literário (bem como de outras manifestações culturais) pode ser apreendida também em termos de funções e conteúdos, conforme lembra-nos Levitas (1990). Essa idéia será reforçada com o comentário a seguir sobre entrelaçamentos entre crítica literária feminista e utopia e com o olhar que será direcionado sobre o poema "Fotografia", de Adélia Prado, discutido na última parte.

\section{Crítica literária feminista e utopia}

Tratarei agora das atividades de ler e interpretar obras literárias partindo de uma perspectiva caracterizada como crítica e informada pelo feminismo. Uma breve discussão sobre questões concernentes ao feminismo e à crítica literária feminista ajudará a esclarecer as relações entre essa vertente crítica e a noção de utopia, buscando explicitar uma possível abordagem utópico-feminista. Feminismo tornou-se um termo vago por incorporar, em seus sentidos, uma diversidade de tendências e formas de ação e abordagem. Apesar de essa diversidade apresentar, às vezes, visões contraditórias e conflituosas, o que se tornou bastante visível com o surgimento das muitas vozes conclamando diferenças nos feminismos dos anos 80 e 90 , a comunidade acadêmica feminista compartilha algumas premissas fundamentais. Um desses pontos de convergência reside na preocupação política com o âmbito social, um caráter pragmático (porém não programático) que caracteriza o movimento.

Nos estudos literários feministas, obras pioneiras como $\mathrm{Um}$ Teto Todo Seu (1929), de Virginia Woolf, e O Segundo Sexo (1949), de Simone de Beauvoir - marcos de investigação pelo pioneirismo e escopo, no âmbito do pensamento feminista do século XX - nunca perdem de vista as relações entre práticas textuais e sociais. E, apesar do desenvolvimento, da sofisticação e das mudanças observadas na trajetória da crítica feminista literária e cultural desde a publicação das 
análises iniciais empreendidas por Woolf e Beauvoir, seu foco centrase ainda nas intersecções entre correntes sexuais, textuais e políticas, conforme tão bem colocado por Robyn Warhol e Diane Herndl, na introdução a uma coletânea de textos críticos:

As/os críticas/os feministas geralmente concordam que a opressão das mulheres é um fato da vida, que o gênero deixa traços nos textos literários e na história literária, e que a crítica literária feminista exerce papel importante na luta para eliminar a opressão no mundo fora dos textos (1991).

Esse aspecto foi reforçado por Gerardine Meaney, que aponta ser exatamente tal propósito político comum o combustível da proposta acadêmica feminista:

A natureza [dos] elos que unem [a produção acadêmica] com o ativismo feminista enriquecem a crítica feminista com uma vitalidade que proporciona à critica e aos estudos de gênero o único tipo de coesão aceitável. Subjacente à diversidade intelectual há um propósito político comum, apesar de não único. A comunidade acadêmica feminista não é alcançada sob o signo da renúncia à diferença, mas através da ativação dessa diferença em energia política e intelectual (1993, p. 2).

Essa conexão com o que denominamos "mundo real", característica das teorias feministas, provocou um novo impulso nos estudos literários. O trecho citado exemplifica bem tal aspecto, por meio da escolha dos termos "vitalidade" e "energia".

Isso torna evidentes as relações entre as formas feministas de abordar textos culturais e a noção de utopia. Usando as palavras de Toril Moi, para citar mais uma crítica literária que reitera e sintetiza a linha de pensamento que está sendo traçada, "el principio de la crítica feminista há sido siempre político: tratar de exponer las practicas machistas para erradicarlas" (1995). Crítica à história e projeção de um espaço social melhor são o material da utopia, conforme já salientado. A crítica feminista sonha então com uma história calcada numa outra prática entre os sexos (que não a de hegemonia e opressão que testemunhamos). Age em nome disso. 
Uma possibilidade de leitura utópico-feminista

Prosseguirei essa discussão com uma proposta de ampliação do que foi exposto acima, através da construção de uma forma de leitura que, orientada pela categoria de gênero e partindo de um plano conceitual teórico-feminista, observe criticamente a representação literária do nosso lugar na história e, ao mesmo tempo, abra espaço para a utopia.

O conceito de um "outro lugar" (an elsewhere) do discurso e da representação consiste em um dos modos pelos quais um espaço utópico-feminista foi teorizado. Particularmente útil para o nosso propósito, esse espaço conceitual remete a significados diferentes para diferentes pensadoras. No trabalho de Julia Kristeva (1974), ${ }^{5}$ o "outro lugar" apresenta-se como um espaço no qual as mulheres não se identificariam com a ordem simbólica (a lei do pai), nem seriam inspiradas por aquilo que essa ordem reprime, ato cuja consequiência seria a vitimização. O "outro lugar" para Kristeva seria um espaço no qual as mulheres poderiam identificar-se com o que foi reprimido pelo contrato simbólico, porém sem que figurassem como vítimas. Tal posição é desejável, mas não está disponível historicamente, apesar de poder ser percebida através dos irrompimentos semióticos inscritos na linguagem poética. O maior obstáculo implícito nessa teorização da noção do "outro lugar" é que ela parece operar uma equação entre as mulheres e um excesso semiótico (que se opõe a e ao mesmo tempo desestabiliza o contrato simbólico), arriscando assim aprisionar as mulheres exatamente no espaço que elas têm historicamente ocupado. Outro perigo da equação entre o feminino e o "semiótico" (que, por sua vez, possui forte relação com o inconsciente) reside na implicação, dela decorrente, de que a ordem simbólica da linguagem seja intrinsecamente opressora e hegemônica. ${ }^{6} \mathrm{De}$ fato, na fusão entre o ser mulher e o não-lugar da linguagem, a teoria de Kristeva arrisca transformar esse ser feminino na própria utopia (em contraposição à

5 “About Chinese Women” In: The Kristeva Reader, Toril Moi ed. 1986, p. 139-158.

6 Essa crítica tem sido feita repetidamente por leitoras de Kristeva. Ver, por exemplo, a "Introduction", de Toril Moi. In: The Kristeva Reader, 1986, p. 1-22, Felski 1989, Braidotti 1991. 
visão deste ser enquanto sujeito histórico crítico e desejante da utopia). Contudo, esse "excesso semiótico" perceptível na linguagem literária poder ser lido com vistas à operacionalização de uma função utópica, podendo então gerar uma leitura positiva, ponto que será discutido adiante.

"Sorties" (1975), ' de Hélène Cixous, explora a idéia de um "outro lugar" enquanto espaço feminino que seja verdadeira e radicalmente "outro", em oposição à alteridade histórica das mulheres ditada pela lógica do falogocentrismo. Apesar de esse fio de pensamento apresentar uma contradição semelhante à comentada acima, o argumento de Cixous toca numa questão importante para a presente discussão: a centralidade da escritura feminina no processo de busca do "outro lugar" utópico:

Deve haver algum outro lugar, digo a mim mesma. E todos sabem que para ir a algum outro lugar há rotas, sinais, "mapas" - para uma exploração, uma viagem. Livros são isto. Todos sabem que um local existe que não seja economicamente ou politicamente comprometido com toda a baixeza. Que não seja obrigado a reproduzir o sistema. A escritura é isto. Se há um outro lugar capaz de escapar à repetição infernal, encontra-se naquela direção, onde ela [a escritura] inscreve-se a si mesma, onde ela sonha, onde ela inventa novos mundos (1975, p. 72).

Para Cixous, esse "outro lugar" existe na escritura enquanto espaço "onde o desejo faz a ficção existir" (1975, p. 97). Ela está se referindo à escritura femi “ina (l'écriture féminine) em oposição a uma tradição literária falocêntrica que cai em repetição narcísica. Ao mesmo tempo em que a idéia de uma alteridade histórica radical calcada numa economia 'verdadeiramente feminina' que escapa à codificação, configura uma barreira intransponível para os debates e teorias feministas (como também o faz o conceito do "semiótico" proposto por Kristeva), Cixous expõe uma relação entre o desejo por um "outro lugar" e a escritura, fator que oferece uma forma de se pensar o desejo utópico por um espaço de alteridade radical como

7 In: Cixous e Clément The Newly Born Woman, 1996, p. 63-132. 
consistindo precisamente naquele elemento que motiva a escritura ("faz a ficção existir").

Apesar das diferenças em suas elaborações teóricas, as definições do "outro lugar" de autoria de Cixous e Kristeva podem ser lidas paralelamente, pois, para as duas pensadoras, esse espaço utópico emerge na escritura: nos irrompimentos semióticos da linguagem poética e na escritura feminina. Observa-se outra convergência no sentido em que elas sugerem alteridades históricas radicais, estando, portanto, em sintonia com o conceito Blochiano do porvir (o "ainda-não"), ou aquilo que é totalmente novo e que pode ser vislumbrado em determinadas manifestações culturais. Defendo que esse elemento pode, e deve, ser apropriado em leituras feministas.

A filósofa e crítica feminista Luce Irigaray fala de uma perspectiva diferenciada. Para ela, esse "outro lugar" configura-se enquanto espaço liminar, melhor definido em termos de movimentos estratégicos do que de um posicionamento fixo: "um pé no sistema, outro fora", nas palavras de Rosi Braidotti (1991, p. 172). Tal posição dual, "travessia lúdica e desestabilizadora que permitiria à mulher a resdescoberta do lugar de sua 'auto-estima"” (IRIGARAY, 1977, p. 77), está implícita no jogo da mimese, compreendida por Irigaray enquanto re-encenação da condição, ou da existência, de mulher que se mostra "capaz de trazer novos elementos a essa construção" (1977, p. 76). Esse jogo pode promover o desmantelamento da ordem (fálica) vigente por ter a capacidade de "acrescentar uma perspectiva crítica na nossa cultura em crise, bem como oferecer um ponto de partida para uma análise radicalmente nova dessa cultura" (BRAIDOTTI, 1991, p. 172). Diferentemente da noção do "outro lugar" do feminino à la Kristeva e Cixous, de acordo com Irigaray, tal espaço funciona a partir do interior mesmo das estruturas conceituais e sociais pré-existentes, envolvendo um movimento simultâneo de repetição e desafio.

Outra pensadora feminista que investigou as possibilidades do conceito do "outro lugar" das (e para as) mulheres foi Teresa de Lauretis. Assim como Irigaray, sua visão desse espaço também é definida em relação a um estado de liminaridade (implicando, portanto, um posicionamento duplo para uma subjetividade feminina) e perspectivada a partir de estruturas e instituições vigentes: 
Penso [nesse "outro lugar"] enquanto espaços às margens dos discursos hegemônicos, enquanto espaços sociais escavados nos interstícios das instituições e nas fendas e rachaduras dos aparatos do poder/saber. E é aí que podem ser estabelecidos os termos de uma construção de gênero diferenciada - termos que agem efetivamente nos níveis da subjetividade e da autorepresentação: nas práticas micro-políticas da vida diária e nas ações de resistência do quotidiano que proporcionam tanto formas de agência quanto fontes de poder, ou investimentos que possam resultar em poder; e nas produções culturais de mulheres, feministas, que inscrevem aquele movimento para dentro e para fora da ideologia, aquela travessia de fronteiras - e dos limites - da(s) diferença(s) sexuais (1987, p. 25, grifos meus).

Percebe-se um forte sentido de imediação (e imediações) nas visões de De Lauretis e de Irigaray. De acordo com essas pensadoras, o "outro lugar" é, de certa forma, o aqui e agora do nosso ambiente social androcêntrico e distópico. Elas falam sobre possíveis instâncias críticas, movimentos estratégicos, posicionamentos liminares. Pode-se afirmar que suas teorias são utópicas, no sentido em que buscam desmantelar estruturas falocêntricas (Irigaray) e reconstruir noções de gênero (De Lauretis). Apesar de teorizado nas décadas de 70 e 80, o posicionamento contraditório proposto por ambas para o sujeito feminista tem tido impacto na teoria feminista mais recente (BRAIDOTTI, 1991; FUNCK, 1998).

Informada pelo que foi exposto acima, proponho a construção de uma hermenêutica utópico-feminista, baseada nessas duas noções do "outro lugar" do feminino que podem ser vistas como complementares: a. um espaço de alteridade radical na escrita e na representação onde o desejo se inscreve, quer dizer, o "outro lugar" que motiva a própria escritura; e b. um espaço liminar que, ao situarse dentro e fora das estruturas existentes, permite às mulheres perspectivas críticas e ações transformadoras. Enquanto na primeira orientação, o horizonte utópico busca escapar de teorizações, a segunda abre caminhos para a formulação de noções de utopias enquanto construções parciais, provisórias, processuais e ideológicas, aspectos cruciais para os debates contemporâneos sobre feminismo e 
utopia. Percebo essas orientações enquanto tendências inextricavelmente ligadas, em constante complementaridade e fluxo, referindo-me a elas em separado por propósitos analíticos.

O "outro lugar" de uma "Fotografia"

O poema "Fotografia", de Adélia Prado ${ }^{8}$, em que um eu-lírico debruça-se sobre a fotografia da mãe e compartilha suas impressões com as/os leitoras/es, se nos apresenta, de forma mais imediata, como uma construção dicotômica, polarizada entre a repetição de uma ordem dominante que segue a lógica de poder vigente e uma disposição utópica subversiva dessa ordem e indicadora de uma alteridade histórica. Eis o texto:

\section{Fotografia}

Quando minha mãe posou

Para este que foi seu único retrato,

Mal consentiu em ter as têmporas curvas.

Contudo, há um desejo de beleza no seu rosto

que uma doutrina dura fez contido.

A boca é conspícua, mas as orelhas se mostram.

$\mathrm{O}$ vestido é preto e fechado.

O temor de Deus circunda seu semblante, como cadeia. Luminosa. Mas cadeia.

Seria um retrato triste

Se não visse em seus olhos um jardim.

Não daqui. Mas jardim.

Figuram, na descrição da fotografia, elementos sugestivos dos processos de apagamento e de repressão historicamente impostos às mulheres. O poema indica ter sido esse o "único retrato" feito, em que "uma doutrina dura" conteve a expressão de "um desejo de beleza". O

Em sua Poesia Reunida (1992). 
contexto em que a fotografia foi tirada demandava gravidade nas feições do rosto e na vestimenta ("a boca é conspícua", "o vestido é preto e fechado"). E notável também, através de um viés marcadamente religioso, é o mecanismo de repressão manifestado pela símile contida nos versos 9 e 10: "o temor de Deus" que se impõe, "[circundando aquele] semblante como cadeia".

Estruturalmente construída por antíteses, evidencia-se, na descrição da fotografia, a oposição das idéias entre a menção aos processos repressores acima descritos e a sutil sugestão de um "outro lugar" do discurso e da representação, sinalizado textualmente através do emprego das adversativas "contudo" e "mas", nos versos 4, 7 e 13. Essa construção reforça a tensão dual entre o "aqui" histórico contextual dessa fotografia de mulher e o seu "outro lugar":

uma doutrina dura

a boca conspícua

o temor de Deus / cadeia

$o$ "aqui" do retrato um desejo de beleza

As orelhas [que] se mostram

a luminosidade

o jardim

Essa oposição também pode ser observada através do sofisticado uso da pontuação no verso 10 , em que a "luminosidade" está contida entre pontos finais, que nos fazem lembrar as grades da "cadeia" através das quais a luz se derrama; bem como pela própria disposição do poema na página, pois, enquanto uma margem reproduz a retidão da "moldura" mimetizando uma rigidez repressora, na outra, os versos apontam para fora dessa "moldura" feito setas.

Esse "outro lado" da foto, indicador de um espaço não disponível naquele momento histórico para o sujeito fotografado, não pode ser lido exatamente como equivalente aos irrompimentos semióticos inscritos na linguagem poética, conforme teorizou Kristeva, uma vez que esses últimos estariam manifestados textualmente através de quebras e rupturas no âmbito do verbal e da

9 Registro um agradecimento a Izabel Brandão e a Cecília Cunha que, presentes na sessão de comunicações em que estas reflexões foram expostas, no X Seminário Nacional e I Seminário Internacional Mulher e Literatura (João Pessoa, 2003), teceram os comentários relativos à pontuação do verso 10 e ao aspecto visual do poema. 
sintaxe, o que não chega a ocorrer no poema de Prado. Pode-se, porém, argumentar a favor de uma leitura desse "outro lugar" do poema, enquanto espaço de alteridade radical do feminino, ao observarmos a sutileza na escolha das imagens poéticas que nos fazem vislumbrá-lo sem que ele seja descrito. As referências a "um desejo de beleza" e a "um jardim não daqui", ambas de conteúdo fortemente utópico, uma vez que utopia pode ser definida enquanto expressão do desejo (LEVITAS, 1990) e tem sido imaginada na cultura ocidental através de jardins "famosos" (do Éden e das Delícias, por exemplo), condizem com um modo catacréstico de escritura, ao apontarem para o indizível da linguagem, que é, paradoxalmente, expresso através da própria linguagem. Há, nesse silêncio paradoxal, a inscrição de uma dinâmica textual do desejo utópico, ${ }^{10}$ bem como um possível alinhamento com o espaço do "semiótico" teorizado por Kristeva e com o "outro lugar" da escritura, onde, segundo Cixous, "o desejo faz a ficção existir." (Sendo o termo "ficção" aqui entendido de forma mais ampla, como sinônimo do fazer literário de modo geral.)

Uma outra forma de observarmos o "outro lugar" dessa fotografia resulta da consideração daquilo que excede a moldura do retrato, ou seja, da reflexão sobre a "moldura do poema" (em contraposição à moldura da foto), que recorta o posicionamento do eulírico contemplando a imagem da mãe e compartilhando suas impressões com as/os leitoras/es. Evidencia-se aí a questão da recepção. Perspectivado a partir deste ângulo, o nosso olhar adquire a dimensão de um terceiro plano: olhamos um olhar (o do eu-lírico) que olha ainda um outro (o da imagem da mãe). O mise-en-abîme quebra a dualidade apenas aparente advinda de uma primeira leitura do poema, sofisticando-o e problematizando-o.

A discussão a seguir, orientada pelo movimento de dentro para fora da fotografia, objetiva relacionar esse jogo poético em três dimensões e a segunda forma de teorizar o "outro lugar" enquanto espaço liminar que, ao situar-se dentro e fora das estruturas existentes,

10 Sobre a qualidade catacréstica da beleza em literatura, ver Barthes, 1970; e sobre a centralidade dessa figura de linguagem na escritura utópica, Cavalcanti, 1999. 
permite a construção de perspectivas críticas e ações transformadoras em termos de relações de gênero.

Já foram expostas acima as formas pelas quais a descrição da imagem na fotografia é construída enquanto posicionamento dual, com "um pé no sistema, outro fora", nas palavras já citadas de Braidotti. Essa situação pode ser percebida enquanto indicadora de uma situação liminar e estratégica, que repete uma ordem hegemônica pré-existente, subvertendo-a pela presença de um excesso não domesticado (e também inarticulado/ável).

Num segundo nível, naquele em que é observado o local de enunciação do poema (ou seja, o local da fala do eu-lírico), enfatize-se que o poema apresenta uma crítica à nossa cultura, ao oferecer novos pontos partida para sua análise. Esse direcionamento é montado não apenas a partir do recorte, diferenciado e gendrado, do objeto cultural examinado (a única foto da mãe), trazendo à superfície o que existia até então nas "fendas e rachaduras dos aparatos do poder/saber" - e que tão bem pode metaforizar a nossa ação enquanto críticas literárias, traçando uma arqueologia do que havia sido negligenciado enquanto presença do feminino na cultura -, mas também pela apresentação de uma re-leitura do retrato em busca dos elementos utópicos, ou dos excessos, desafiadores da ordem que o produziu.

Orientando agora a leitura a partir do terceiro nível, aquele que abarca as relações entre o texto do poema e suas/seus leitoras/es, faz-se interessante reler os últimos versos de um outro poema, "A arte de ser feliz", de Cecília Meireles, no qual figura um eu-lírico rememorando "as pequenas felicidades" encontradas em várias janelas vida afora:

quando falo dessas pequenas felicidades certas, que estão diante de cada janela, uns dizem que essas coisas não existem, outros que só existem diante das minhas janelas e outros, finalmente, que é preciso aprender a olhar, para poder vê-las assim (Grifos meus).

Esse texto nos fala do aprendizado do olhar, que é o ponto de convergência com o argumento que pretendo levantar: o de que um dos efeitos dos poemas de Meireles e de Prado, em nível de recepção, é o de que, a partir da identificação entre o eu-lírico e o/a leitor/a empírico/a, possa haver uma "educação do olhar", no sentido de se 
buscar, nos objetos da nossa cultura, aqueles elementos que apontam para os limites das ideologias e para os excedentes utópicos. Essa aproximação entre o eu-lírico e o/a leitor/a resulta tanto da própria voz desse "eu", quanto da intimidade gerada pela estratégica escolha da poeta ao descrever uma situação em que o íntimo é compartilhado no ato de se perscrutar fotografias de família. Assim, tem-se uma dimensão de como pequenas práticas do quotidiano podem adquirir uma qualidade de ação micro-política imediata, de ato de sobrevivência diante das nossas distopias.

\section{Referências}

BARTHES, Roland. S/Z. Trans. Richard Miller. Londres: Jonathan Cape, 1970.

BLOCH, Ernst. The principle of hope. Trans. N. Plaice, S. Plaice \& P. Knight. Cambridge, Mass: MIT, 1995.

BRAIDOTTI, Rosi. Patterns of dissonance: a study of women in contemporary philosophy. Trans. Elizabeth Guild. Cambridge: Polity,
1991.

CAVALCANTI, Ildney. A distopia feminista contemporânea: um mito e uma figura. In Muzart, Zahidé (org.). Boletim do GT A Mulher na Literatura. Vol. 9. Florianópolis: ANPOLL/UFSC, 2002.

CAVALCANTI, Ildney. Articulating the elsewhere: utopia in contemporary feminist dystopias. Tese de Doutoramento. University
of Strathclyde, Glasgow, Escócia, 1999.

CIXOUS, Hélène. Sorties. In Cixous, Hélène \& Clément, Catherine The newly born woman. Trans. Betsy Wing. London: Tauris, 1996
(1975).

FELSKI, Rita. Beyond feminist aesthetics: feminist literature and social change. London: Hutchinson Radius, 1989. FUNCK, Susana. Feminist literary utopias. Florianópolis: UFSC,
1998.

HONDERICH, Ted ed. The Oxford companion to philosophy. Oxford and New York: Oxford University Press, 1995. 
IRIGARAY, Luce. This sex which is not one. Trans. Catherine Porter. Ithaca, New York: Cornell U.P., 1996 (1977).

KRISTEVA, Julia. About chinese women. In Moi, Toril ed. The Kristeva reader. Oxford: Blackwell, 1986 (1974).

DE LAURETIS, Teresa. Technologies of gender: essays on theory, film and fiction. London: MacMillan, 1989 (1987).

LEVITAS, Ruth. The concept of utopia. Hempstead: Philip Allan, 1990.

MEANEY, Gerardine. (Un)Like subjects: women, theory, fiction. London \& New York: Routledge, 1993.

MOI, Toril. Teoría literaria feminista. Madrid: Cátedra, 1995.

PRADO, Adélia. Poesia reunida. São Paulo: Siciliano, 1992.

$\mathrm{RICH}$, Adrienne. Adrienne Rich's poetry and prose. Sel. and ed. Barbara and Albert Gelpi. New York and London: W.W. Norton and Co., Inc., 1993.

SARGISSON, Lucy. Contemporary feminist utopianism. London: Routledge, 1996.

WARHOL, Robyn \& HERNDL, D. P. eds. Feminisms - An anthology of literary theory and criticism. New Brunswick, New Jersey: Rutgers University Press, 1991. 